\title{
Dental hygienists: working patterns and job satisfaction
}

\author{
A national survey of dental hygienists: working patterns and job satisfaction by D. E. Gibbons, M. Corrigan and \\ J. T. Newton Br Dent J 2001; 190:207-210
}

\section{Objective}

To describe the working practices and level of job satisfaction of dental hygienists in the United Kingdom.

\section{Design}

Postal questionnaire survey of 3,955 dental hygienists registered with the General Dental Council. Replies were received from $2,533(64 \%)$.

\section{Results}

At the time of the survey only a small proportion of respondents (11\%) were not working as dental hygienists, the most common reason for a current career break being child rearing. The majority of dental hygienists (78\%) were employed in general dental practices, and most worked in more than one practice (64\%). Approximately half worked part-time (fewer than 30 hours per week), and part-time working was more common amongst those respondents with childcare responsibilities. In the region of $60 \%$ of respondents had taken one or more career breaks during their working life, and the average total duration of career breaks was 11 months, the most common reason for all career breaks was child rearing. Additional qualifications had been gained by $35 \%$ of the sample, a high proportion (75\%) had attended training courses in the previous year. The respondents expressed a high degree of job satisfaction, those who were older and who had childcare responsibilities expressed higher levels of job satisfaction.

\section{Conclusions}

Dental hygienists express a high level of job satisfaction. A proportion take breaks in their career, most commonly for pregnancy and child rearing. The majority return to part-time employment after their career break. Planning of future requirements for the training of professionals complementary to dentistry should be informed by a consideration of the working patterns of dental hygienists.

\section{In brief}

- Dental hygiene offers a potentially rewarding career. High levels of job satisfaction were expressed by the dental hygienists surveyed. Those who had childcare responsibilities, and those who were older expressed higher degrees of job satisfaction.

- Approximately $10 \%$ of hygienists registered with the GDC were not currently working as hygienists.

- Childcare responsibilities have a significant impact upon the careers of dental hygienists. Child rearing was the most commonly cited reason for taking a career break, and those with childcare responsibilities were more likely to work fewer than 30 hours per week.

- A large proportion of dental hygienists continue their professional development post-qualification. Approximately $75 \%$ reported attending a training course in the previous year - most commonly a scientific meeting.

\section{Comment}

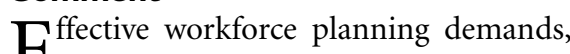
Eamongst other things, accurate information on the role, career patterns and job satisfaction of the professional group involved. This large scale survey confirms earlier smaller studies and goes a long way towards providing the necessary information for this group of PCDs. The apparent simplicity of postal questionnaire surveys belies the complex problems involved with their preparation and analysis. Is the questionnaire sent to the most appropriate people? Are the questions unambiguous and understood by all the recipients in the same way? Do the non-responders introduce significant bias into the results?

A survey of currently registered hygienists provides no information on the numbers or the reasons why those who are not currently registered have given up their careers. Similarly the $36 \%$ of subjects who did not respond may have introduced bias. It is pleasing, therefore, that this large scale survey substantiates the results of other smaller surveys, some of which sought to include hygienists who have given up practice.

Historically, dental hygiene has been a very attractive profession for dental nurses and some of the reasons for this will be found in this paper. In particular, the possibility of working part-time in a variety of working environments and secure employment prospects must play their parts. High levels of job satisfaction have been confirmed, indicating a well motivated workforce. At the same time, half the respondents reported working part time, bearing out the opinion that a career in dental hygiene can be successfully combined with child rearing.

An increasing number of schools of dental hygiene are combining dental hygiene and dental therapy courses. In future surveys such as this one, it will be interesting to see whether increasing the range of permitted duties and extending permission for therapists to work in general dental practice will enhance job satisfaction. Indeed, a devil's advocate may ask the question; 'Will PCDs of the future be using the full range of skills they have been taught, or will they continue to work primarily as hygienists?' This paper provides the baseline data against which we can compare future studies aimed to assess the career patterns of these valued members of the dental team whose roles are currently evolving so rapidly.

\section{G. Hillam}

Consultant in Restorative Dentistry, Director, School of Dental Hygiene. Liverpool University Dental Hospital 